\title{
Providing Academic Leadership in Universities in Cross River State, Nigeria: Assessment of Departmental Heads' Effectiveness
}

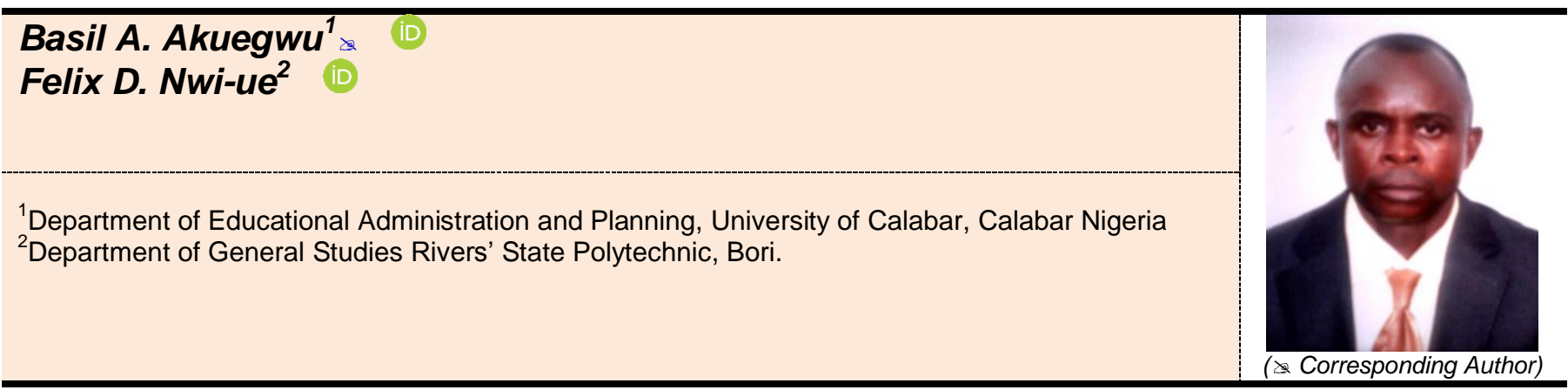

\begin{abstract}
This study assessed Heads of Departments' effectiveness in providing academic leadership at the departmental level. I research question and 2 hypotheses were formulated to give direction to this investigation. Survey design was adopted for the study. The population of the study comprised 110 Heads of Departments from 2 universities in Cross River State who were purposively constituted into the sample. Data were collected using "Academic Leadership Effectiveness Assessment Questionnaire (ALEAQ)" constructed by the researchers. Data obtained were subjected to statistical analysis using Descriptive Statistics (X and SD), Population t-test of single mean and Independent t-test statistical techniques. Results obtained indicated that HODs are most effective in providing academic leadership in the aspect of providing professional development, while they are least effective in strengthening leadership skills; HODs' effectiveness in providing academic leadership at the departmental level is significantly low; type of university does not significantly influence HODs' effectiveness in providing academic leadership at the departmental level. It was therefore recommended, amongst others that Heads of Departments should be given orientation at the time appointment and retreat organised for them from time to time to equip them with the necessary skill to provide academic leadership.
\end{abstract}

Keywords: Heads of departments, Academic leadership, Effectiveness, Administration, Universities.

\section{Contents}

1. Introduction

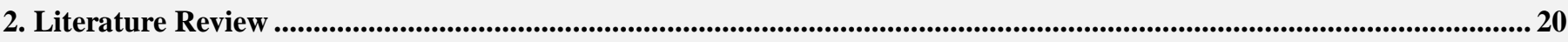

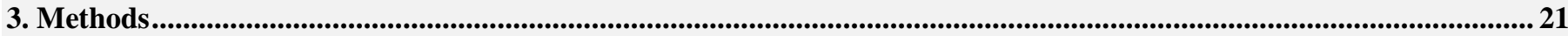

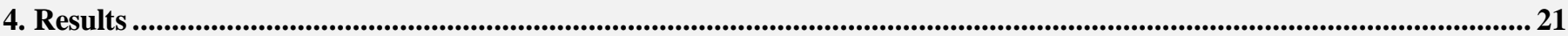

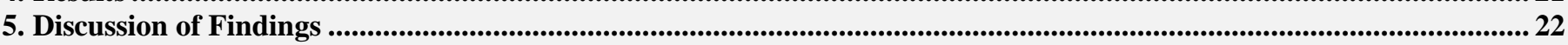

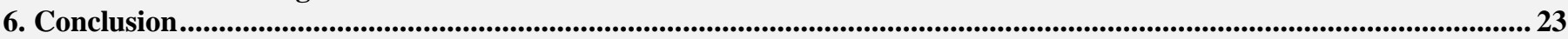

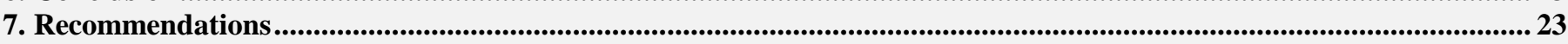

References ........... 24

Citation | Basil A. Akuegwu; Felix D. Nwi-ue (2017). Providing Academic Leadership in Universities in Cross River State, Nigeria: Assessment of Departmental Heads' Effectiveness. Asian Journal of Education and Training, 3(1): 18-24.

DOI:

ISSN(E) :

Licensed:

10.20448/journal.522/2017.3.1/522.1.18.24 Crossref

Contribution/Acknowledgement: All authors contributed to the conception and design of the study.

Funding: $\quad$ This study received no specific financial support.

Competing Interests:

Transparency:

The authors declare that they have no conflict of interests.

History:

The authors confirm that the manuscript is an honest, accurate, and transparent account of the study was reported; that no

Publisher:

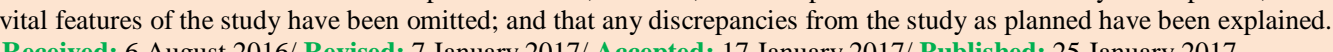
Received: 6 August 2016/ Revised: 7 January 2017/ Accepted: 17 January 2017/ Published: 25 January 2017

Asian Online Journal Publishing Group 


\section{Introduction}

Universities all the world are undergoing change brought about by science and technology. These changes are experienced in all aspects of university life. The ability to respond positively to these changes places one university above the other. Thus, universities have found themselves in a competitive mood, whereby each strive to outclass others and have competitive advantage over them through reformation, transformation, modification and outright over-hauling of their academic programmes and organisation structures to meet global requirements. In a bid to catch up with others and remain relevant, universities in Nigeria are having critical reassessment of their tripartite core mandates of teaching (knowledge transmission), research (knowledge generation) and community service (knowledge application). However, one thing is to reassess the trifocal functions, another is to let the outcome stand the test of time. To realize this calls for proactiveness in university administration. This is because administration is central to effective functioning of universities. Without it, university existence has the tendency to pale into insignificance.

University administration is categorized into top or strategic management made up of the Vice Chancellor and other principal officers, middle or tactical management made up of Deans of Faculties and Directors of Institutes, and junior or operational management made up of Heads of Departments. Each of these three categories plays important roles in university administration, and so is indispensible. While the roles of the three categories of university administration are important, those of heads of departments remain outstanding. This is because the department is the basic academic unit of the university where implementation of policies regarding students' learning outcomes are carried out, and so is particularly important in the determination of professional values and academic expertise (Barakonyi, n.d). Interestingly, students' learning outcomes fall under the purview of teaching function, which standout as the "primus enta paris" (first among equals) of the trifocal functions and it constitutes, first and foremost, the main essential demand by university education (Akuegwu, 2015). Teaching function takes place mainly at the departmental level and is central to the delivery of university mandate. It is closely followed in this regard by research function. These two functions in most cases define the academic position of universities and the essence of their existence. However, teaching and research functions need to be properly coordinated at the departmental level in order for them to achieve the desired results. This is where academic leadership derives its pride of place.

Academic has to do with scholarly activities or practices such as classroom teaching and learning, and research projects designed by a school or university to enhance students' learning outcomes. These activities are more prominent in the departments. Leadership, on the other hand, is the ability to inspire confidence and support, influence, motivate and enable people to contribute towards the effectiveness and success of the organisation of which they are members (Kim and Mauborgne, 1992; House, 2004). Therefore academic leadership is the ability to develop leading ideas and the formation of new academic directions, and inspiring others by being a role model, self aware, self reflective as well as being decisive, visionary, planning ahead and handling finances (Berg and Jarbur, 2014) aimed at promoting academic excellence. According to Joyce and O'Boyle (2013) academic leadership is understood to incorporate the core academic functions of teaching/learning and research and scholarship together with a broader focus on academic values and identity. It therefore follows that academic leadership is paramount in departmental administration. This is because it gives direction to teaching/learning and research activities and determines the extent of the achievement of scholarship excellence at the departmental level in particular and university in general. To a great extent, the quality of education that is imparted depends largely on the quality of leaders at various levels within the university from heads of departments to principal officers (Ayuba, n.d).

The onus of academic leadership rests on the shoulders of heads of departments (HODs), who are appointed to coordinate departmental affairs and act as a liaison for the university at the departmental level for a period of three years for professors and two years for other categories of academic staff, with the later serving on acting capacity. The need for academic leadership stems from the fact that universities have continued to undergo significant changes in response to such factors as government policy, continuing growth in demand for ever higher level of academic attainment and credentials, rapid economic development, pervasiveness and society-wide impact of Information and Communication Technologies (ICTs), demand for increased access, internationalization and globalization (Skilbeck, 2001; Bolden et al., 2012; Jones et al., 2012). In furtherance to this, the mandate of universities, which has continued to remain teaching/learning and research has been affected tremendously by the knowledge age resulting to major impact on their operations. It has therefore become imperative for a sound, purpose-driven and articulate academic leadership to give direction to universities starting from the departmental level, to modify from time to time, their goals, missions and methodologies.

According to DuBrin (2010) to lead others effectively is a rare quality. It becomes even rarer at the highest levels in an organisation because the complexity of such positions require a vast range of leadership skills. This is why a person who assumes the role of departmental headship must be visionary and has enormous powers and ability to influence decisions so as to achieve the desired results. Achievement of departmental academic goals effectively rests on the leadership acumen of heads of departments, and so, they receive credit for success and condemnation for failure.

In order to provide academic leadership effectively, departmental heads are required to perform these roles as articulated by Berg and Jarbur (2014) and University of Limerick (n.d): Strengthening leadership skills, Academic Management (Teaching and Research), Resource Management (Teaching Staff and Facilities), Promoting capacity for innovation, Promoting commitment to performance improvement, Providing professional development, Enhancing quality assurance and standard, Providing effective supervision of instruction and Providing leadership for curriculum development. Discharging these roles effectively, HODs have to exercise the power embedded in their position and have the capacity and willingness to influence departmental decisions to achieve the required outcome. It is against this backdrop that this study focuses on assessing departmental heads' effectiveness in providing academic leadership in universities in Cross River State. 


\subsection{Statement of the Problem}

One thing is to provide academic leadership, the other is to exercise the power inherent in the position of headship of departments and influence decisions for the purpose of achieving teaching/learning and research goals. As important and central to effective departmental functioning as teaching/learning and research, heads of departments have not been able to give effective academic leadership to make these two functions stand the test of time. Lecturers often teach their students, administer examinations, grade students and submit results at their own convenience. These have resulted in delay in releasing students' results, prolonging graduation periods for final year students and denying students their right of knowledge of their academic standing at the end of the semester or session. Worse still, the conduct of research has been confined to the dictates of lecturers. These anomalies abound because HODs do not give deadlines and enforce them. Some of them lack knowledge of the powers inherent in their positions to give leadership to teaching/learning and research functions. Even at that, they lack the ability to influence decisions regarding effective conduct of academic activities in their administrative domains.

Realising the handicap of HODs in providing effective academic leadership, the central university administration in the study area have come out with deadlines regarding the conduct of examinations and publication of results. In addition modalities have been initiated to encourage research activities by motivating lecturers through funding and provision of enabling environment. However, as laudable as these efforts are, the expected results have not been achieved. Given this state of affairs, the problem of this study is articulated thus: What is the level of heads of departments' effectiveness in providing academic leadership in universities in Cross River State?

\subsection{Research Question}

Which academic leadership role is HODs most effective in providing?

\subsection{Hypotheses}

1. The effectiveness of HODs in providing academic leadership in their administrative domains is not significantly low.

2. Type of university does not significantly influence HODs' effectiveness in providing academic leadership.

\section{Literature Review}

The politics of successful academic leadership at the departmental level in universities requires that the HODs be effective in exercising their powers in providing leadership to academic-related activities and as well be alive to influencing decision making in the department to achieve academic excellence. To this end, several studies have come up with findings which identified academic leadership qualities HODs need to possess in order to provide effective academic leadership. The qualities identified by the studies include: integrity, courage and passion, trustworthiness, consideration, responsiveness, adaptability; being able to adapt and change to envision alternative futures, to develop people and collaborative partnerships, to create a positive and collegial working atmosphere; being both supportive and able to get necessary support and being able to influence others positively (Sathye, 2004; Drew, 2006; Vilkinas and Cartan, 2006; Bryman, 2007).

Riaz and Haider (2010) in their study revealed that academic leadership is collegial and cut across policy formulation to dictate and guide the teaching/learning activities as well as research productivity in the department. To ensure the success of the policy, HODs need to be close and monitor teaching and learning situation, research and scholarship to ensure that he/she influences decisions about them and motivate academics towards better performance. Similarly, Lyons (2008) reported that in providing academic leadership, HODs are the custodian of academic standards charged with monitoring the departmental curriculum, ensuring that course assignments are judiciously carried out by aligning individual lecturer's talents and areas of specialty with instructional needs, encouraging and supporting continued personal and professional growth of lecturers, and attesting to the adequacy of instruction and research they engage in. Effectiveness in providing academic leadership in these regards demands that HODs exercise their powers and influence decisions to bring about good and quality results in the pursuit of academic programmes. By so doing, lecturers and students become aware of their responsibilities and the likely outcome should there be failure in living up to expectations.

Research finding have revealed that academic leadership effectiveness of HODs hinges on their abilities to implement change and assure quality of academic programmes, lead curriculum review and implement departmental goals and policies (Hesselbein and Goldsmith, 2006). Accordingly they pointed out that HODs' effectiveness in providing the leadership required to implement policies is a function of their perception of the position they occupy or the credibility which they have been able to build or the impression they have been able to create among lecturers and students. These depend on their honesty or integrity, reliability, courage, consistency, creativity, goal-oriented and innovative. Displaying these qualities has the tendency to win the support and cooperation of the lecturers and students, and as such, be in a position to follow the directives of the HODs to achieve departmental academic and scholarship goals.

Head of Departments' positions are created mainly to lead academic activities and enthrone the culture of scholarship where excellence is the hallmark. This is the purpose for which Vice Chancellors appoint persons to those positions, and they do not expect less. Failure to meet up this expectation, not only alters the vision of the university towards academic excellence, but also results to frustration on the part of lecturers and students. It is for this reason that Erkutlu (2008) admonished HODs to be keen on academic achievement of their departments. Proper exercise of their academic leadership responsibilities is capable of enabling departments realize high academic achievements and promote excellent teachings. Undoubtedly, academic departments play important roles in the success of universities and are established to develop, preserve and transmit knowledge. In agreement, Sung (2007) reported that the main focus of academic leadership is to enlist and guide the talents and energies of teachers, students and parents towards achieving common educational goals. Therefore, HODs should be willing to provide 
enabling environment for lecturers to develop and revise their teaching strategies and methods, so as to make the jobs of educating students easier and result-oriented.

\section{Methods}

Cross River State of Nigeria provided the setting for this study. Its capital is Calabar. It is one of the states in South-South geopolitical zone and the oil-rich Niger Delta Region, lying on the coastal axis. Two universities are domiciled in this state - one conventional and the other, specialised. Purposive sampling technique was adopted whereby 110 HODs, who constituted the population, also formed the sample. Breakdown shows that university of Calabar provided 71 HODs, meaning that there are 71 Departments in it, while Cross River University of Technology $($ CRUTECH) had 39 HODs, which means that there are 39 Departments therein. Data collection was carried out with a researchers-constructed instrument titled "Academic Leadership Effectiveness Assessment Questionnaire (ALEAQ)". It had two sections - A and B. Section A contained two demographic variables, while Section B arranged on a 5-point rating scale consists of 44 items, 4 of which measured each of the 11 variables isolated for this study. The instrument was face-validated by 2 former HODs, and 2 experts in measurement and evaluation. A trial test was conducted using 30 HODs from two other tertiary institutions in the state, while Conbach Alpha Method was used to establish the internal consistency, which yielded .81 as the coefficient. This figure was considered reliable for use in achieving the objective of this study. Descriptive Statistics ( $\bar{X}$ and SD), Population ttest of single mean and Independent t-test statistical techniques were used to analyse the data obtained. Results were presented in tables.

\section{Results}

\subsection{Research Question}

Which academic leadership role is Heads of Departments most effective in providing? The variable in this question is academic leadership role. Descriptive statistics ( $\bar{X}$ and SD) were used to answer this question. Summaries of the results are presented in Table 1.

Table-1. Summaries of Mean $\overline{(\mathrm{X})}$ and Standard Deviations (SD) of the responses of HODs regarding their effectiveness in providing academic leadership

$\mathrm{N}=110$

\begin{tabular}{|c|c|c|c|}
\hline Variables & $\mathbf{X}$ & SD & Rank \\
\hline Providing Professional Development & 13.90 & 2.93 & $1^{\mathrm{st}}$ \\
\hline \multicolumn{4}{|l|}{ Resource Management: } \\
\hline Teaching Staff & 13.67 & 3.39 & $2^{\text {nd }}$ \\
\hline Facilities & 13.64 & 3.67 & $3^{\text {rd }}$ \\
\hline Enhancing Quality Assurance and Standards & 13.63 & 3.85 & $4^{\text {th }}$ \\
\hline Promoting Capacity for Innovation & 13.50 & 3.56 & $5^{\text {th }}$ \\
\hline Providing Effective Supervision of Instruction & 13.42 & 4.30 & $6^{\text {th }}$ \\
\hline Providing Leadership for Curriculum Development & 13.39 & 3.18 & $7^{\text {th }}$ \\
\hline \multicolumn{4}{|l|}{ Academic Management: } \\
\hline Teaching & 13.35 & 2.74 & $8^{\text {th }}$ \\
\hline Research & 13.11 & 3.72 & $9^{\text {th }}$ \\
\hline Promoting Commitment to Performance Improvement & 12.30 & 3.76 & $10^{\text {th }}$ \\
\hline Strengthening Leadership Skills & 12.16 & 3.78 & $11^{\mathrm{th}}$ \\
\hline
\end{tabular}

Summaries of the results presented in Table 1 revealed that HODs are most effective in providing academic leadership bothering on providing professional development $\overline{(\mathrm{X}}=13.90)$, followed by resource management in terms of academic staff $\overline{(X}=13.67)$, resource management in terms of facilities $(\bar{X}=13.64)$. In the fourth position is enhancing quality assurance and standards $\overline{(X}=13.63)$, followed by promoting capacity for innovation $\overline{(X}=13.50)$,

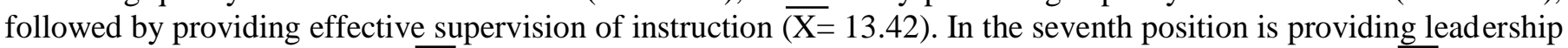
for curriculum development, $\bar{X}=13.39)$, followed by academic management in terms of teaching $(\bar{X}=13.35)$, followed by academic management in terms of research $\overline{(X}=13.11)$. In the tenth position is promoting commitment to performance improvement $\overline{(X}=12.30)$ and lastly strengthening leadership skills $\overline{(X}=12.16)$.

It therefore follows that HODs are most effective in providing academic leadership in the aspect of providing professional development, while they are least effective in strengthening leadership skills. Therefore, providing academic leadership in professional development is what HODs do best in their administrative domains.

\subsection{Hypotheses}

$H_{o I}$. The effectiveness of Heads of Departments in providing academic leadership in their administrative domains is not significantly low. The only variable is HODs' effectiveness in providing academic leadership. Population t-test of single mean is used to analyse data obtained from this variable. Summaries of the results are presented in Table 2. Summaries of the results presented in Table 2 disclosed that the calculated t-values were higher than the critical tvalue of 1.980 given .05 level of significance and 109 degrees of freedom. In specific terms, the calculated t-values were: strengthening leadership skills $(\mathrm{t}=33.710, \mathrm{p}<.05)$, academic management: teaching $(\mathrm{t}=51.092, \mathrm{p}<.05)$, research $(t=36.931, p<.05)$, resource management: teaching staff $(t=42.308, p<.05)$, facilities $(t=38.979, p$ $<.05)$, promoting capacity for innovation $(\mathrm{t}=39.800, \mathrm{p}<.05)$, promoting commitment to performance improvement $(\mathrm{t}=24.001, \mathrm{p}<.05)$, providing professional development $(\mathrm{t}=49.752, \mathrm{p}<.05)$, enhancing quality assurance and standards $(\mathrm{t}=34.099, \mathrm{p}<.05)$, providing effective supervision of instruction $(\mathrm{t}=32.717, \mathrm{p}<.05)$, and providing 
leadership for curriculum development $(\mathrm{t}=44.166, \mathrm{p}<.05)$. With these results, the null hypothesis was rejected and so HODs' effectiveness in providing academic leadership at the departmental level is significantly low.

Table-2.Summaries of Population t-test of single mean analysis of HODs effectiveness in providing academic leadership N = 110

\begin{tabular}{|c|c|c|c|c|}
\hline Variables & $\begin{array}{l}\text { Observed } \\
\text { Mean } \overline{(X)}\end{array}$ & $\begin{array}{l}\text { Assumed } \\
\operatorname{Mean}(\mu)\end{array}$ & SD & $\bar{t}$ \\
\hline Strengthening Leadership Skills & 12.16 & 12.00 & 3.78 & $33.710 *$ \\
\hline \multicolumn{5}{|l|}{ Academic Management: } \\
\hline Teaching & 13.35 & 12.00 & 2.74 & $51.092 *$ \\
\hline Research & 13.11 & 12.00 & 3.72 & $36.931 *$ \\
\hline \multicolumn{5}{|l|}{ Resource Management: } \\
\hline Teaching Staff & 13.67 & 12.00 & 3.39 & $42.308 *$ \\
\hline Facilities & 13.64 & 12.00 & 3.67 & $38.979 *$ \\
\hline Promoting capacity for innovation & 13.50 & 12.00 & 3.56 & $39.800 *$ \\
\hline Promoting commitment to performance improvement & 12.30 & 12.00 & 3.79 & $34.001 *$ \\
\hline Providing professional development & 13.90 & 12.00 & 2.93 & $49.752 *$ \\
\hline Enhancing quality assurance and standards & 13.63 & 12.00 & 3.85 & $34.099 *$ \\
\hline Providing effective supervision of instruction & 13.42 & 12.00 & 4.30 & $32.717 *$ \\
\hline Providing leadership for curriculum development & 13.39 & 12.00 & 3.18 & $44.166^{*}$ \\
\hline
\end{tabular}

A cursory observation of the results indicated that the observed mean $(\overline{\mathrm{X}})$ effectiveness of HODs in providing academic leadership were higher when compared with the assumed mean $(\mu)$ of 12.00. Statistical comparison of the observed mean $(\overline{\mathrm{X}})$ values and the expected mean value $(\mu)$ of 12.00 , using population t-test of single mean yielded positive t-values. This therefore, means that HODs' effectiveness in providing academic leadership at the department level is significantly low.

$H_{o 2}$. Type of university does not significant influence HODs' effectiveness in providing academic leadership. The independent variable is type of university, while the dependent variable is HODs' effectiveness in providing academic leadership. Independent t-test statistical technique is used to compare the mean scores from the two categories of HODs. Summaries of the results are presented in Table 3.

Table-3. Summaries of Independent t-test statistical analysis of the influence of type of universities on HODs' effectiveness in providing academic leadership at the departmental level

\begin{tabular}{|c|c|c|c|c|c|}
\hline \multicolumn{6}{|c|}{ Type of university } \\
\hline & \multicolumn{2}{|c|}{ Conventional } & \multicolumn{2}{|c|}{ Specialized } & \multirow[b]{3}{*}{$\mathbf{t}$} \\
\hline & \multicolumn{2}{|c|}{$\mathrm{N}=71$} & \multicolumn{2}{|c|}{$\mathrm{N}=39$} & \\
\hline Variables & $\overline{(\mathbf{X})}$ & SD & $\overline{(\mathbf{X})}$ & SD & \\
\hline Strengthening Leadership Skills & 12.30 & 3.69 & 11.92 & 3.99 & .492 \\
\hline \multicolumn{6}{|l|}{ Academic Management: } \\
\hline Teaching & 13.48 & 2.72 & 13.14 & 2.79 & .640 \\
\hline Teaching Staff & 13.82 & 3.39 & 13.41 & 3.42 & .600 \\
\hline Facilities & 13.89 & 3.51 & 13.18 & 3.95 & .968 \\
\hline Promoting capacity for innovation & 13.72 & 3.45 & 13.10 & 3.75 & .867 \\
\hline Promoting commitment to performance improvement & 12.11 & 3.82 & 12.64 & 3.77 & -.679 \\
\hline Providing professional development & 14.07 & 2.94 & 13.59 & 2.92 & .822 \\
\hline
\end{tabular}

Summaries of the results presented in Table 3 revealed that the calculated t-values were lower than the critical tvalue of 1.980 given .05 level of significance and 108 degrees of freedom with respect to strengthening leadership skills $(\mathrm{t}=.492, \mathrm{p}>.05)$, academic management: teaching $(\mathrm{t}=.640, \mathrm{p}>.05)$, research $(\mathrm{t}=.815, \mathrm{p}>.05)$, resource management: teaching staff $(\mathrm{t}=.600, \mathrm{p}>.05)$, facilities $(\mathrm{t}=.968, \mathrm{p}>.05)$, promoting capacity for innovation $(\mathrm{t}=$ $.867, \mathrm{p}>.05)$, promoting commitment to performance improvement $(\mathrm{t}=-.697, \mathrm{p}>.05)$, providing professional development $(\mathrm{t}=.822, \mathrm{p}>.05)$, enhancing quality assurance and standards $(\mathrm{t}=.436, \mathrm{p}>.05)$, providing effective supervision of instruction $(\mathrm{t}=-.401, \mathrm{p}>.05)$ and providing leadership for curriculum development $(\mathrm{t}=1.465, \mathrm{p}>$ $.05)$. With this result, the null hypothesis was not rejected, and so, type of university does not significantly influence HODs' effectiveness in providing academic leadership at the departmental level.

Further examination of the results indicated that HODs from the conventional university had higher mean values in 9 of the variables studied. In contrast, HODs from the Specialized University had higher mean values in 2 of the variables.

\section{Discussion of Findings}

Summaries of the results in Table 1 revealed that HODs are most effective in providing academic leadership in the aspect of providing professional development and least effective in strengthening leadership skills. This by implication means that HODs are alive in providing professional development than any other responsibility associated with providing academic leadership at the departmental level. 
This finding suggests that HODs invest more of their time and resources in providing for professional development of themselves and the lecturers. By so doing, they acquire more knowledge, technique and experience to undertake their academic leadership roles effectively. In the case of lecturers providing for their professional development implies that HODs believe in updating of knowledge to enable them be abreast with the latest techniques and development in teaching or instructional delivery; assets which lecturers need essentially to discharge their teaching responsibilities effectively.

This outcome is in line with the findings of Chase (2005) that academic staff feel that their development is greatly affected by freedom to attend conferences (professional development) as this enhances their professional status and raises their awareness of new developments in the field. This must have informed the desire of HODs to provide for professional development of lecturers more than any other responsibility.

Interestingly, this finding reported that HODs are least effective in strengthening leadership skills. This must have accounted for poor academic outcomes among students and lack of commitment to duty among lecturers. This outcome can be explained from the fact that a lot of politics is involved in the appointment of HODs. Often, lecturers who are close to the apex internal administration are appointed to this position disregarding the policy of appointing the most experienced lecturer in the department. Therefore, those who are unduly favoured in this appointment, without the requisite administrative experience shall only display least effectiveness in strengthening leadership skills, and so are not able to provide academic leadership in their departments.

Summaries of the result of hypothesis 1 displayed in Table 2 indicated that HODs effectiveness in providing academic leadership at the departmental level is significantly low. By implication, this finding had it that HODs are not very effective in providing academic leadership in their departments.

This finding suggests that HODs are not living up to expectation in discharging their academic leadership responsibilities. That is, they add little or no value to academic activities because of their failure to provide academic leadership or influence decisions on it. Perhaps, this accounts for laxity on the part of some lecturers in discharging their instructional responsibilities, a situation that has resulted in late submission of students' results, inability to cover course outlines and graduate students on time. The departments are more or less operating in a manner devoid of clear cut policy directives and the will power to enforce decisions.

Failure to provide effective academic leadership in the departments by HODs can be attributed to lack of exposure to the dictates of their jobs prior to appointment. This articulation is corroborated by Lussier and Achua (2007) who reported that Heads are often uncertain about their roles and that no one explained what was expected of them in this position which they assumed without the benefit or advantage of any leadership or managerial training. It therefore followed that HODS were sentenced to failure right from the onset of their assignments. The low effectiveness of HODs in providing academic leadership in the departments is not a fault of theirs. The university system programmed it to be so.

Summaries of the results of hypothesis 2 displayed in Table 3 showed that type of university does not influence HODs' effectiveness in providing academic leadership in the departments. This means that the type of university does not determine the effectiveness of HODs in providing academic leadership. Whether HODs are effective or not does not depend on their university of affiliation. The reason for this finding is that universities operate the same policies regarding the appointment of HODs and so, there is no likelihood of type of university influencing HODs effectiveness in providing academic leadership.

Ordinarily, one would have expected the type of university HODs belong to dictate their effectiveness in providing academic leadership to their departments. Conventional universities with more liberal academic programmes, and therefore have more latitude in their decision making are expected to provide better enabling environment for HODs to showcase their academic leadership effectiveness. In contrast, the specialized universities with more of a single programme of study, although with many branches, are expected to be guided by their nature in discharging their responsibilities. Thus, technology-based university (one of the universities studied) is supposed to tailor the operations of the departments particularly, academic leadership towards fulfilling their mandate of providing technology-based education. So, this role tends to be confined to the nature of their programme. In this case, conventional university is favoured to have more robust environments, and so, HODs in them are likely to be more effective in providing academic leadership. This articulation explained why HODs from conventional university had higher mean effectiveness in providing academic leadership than their specialized university counterpart.

Another plausible reason for HODs from conventional university having higher mean values in their effectiveness in providing academic leadership might be that conventional university has been in existence for more than twenty-five years before the specialized university was established. So, their long period of existence might have provided more experience for their HODs to display their academic leadership effectiveness.

\section{Conclusion}

The finding of this study have clearly shown that HODs are most effective in providing professional development for their lecturers and least effective in strengthening leadership skills in their academic leadership responsibilities. Despite this, they were low in their effectiveness in providing academic leadership, and their type of university does not influence their effectiveness in providing academic leadership. Apart from being low in their effectiveness in providing academic leadership in their departments generally, they displayed effectiveness in providing professional development. Therefore HODs in the area of study are not totally failures in providing academic leadership in their departments, they recorded some degrees of success.

\section{Recommendations}

Arising from the findings, the following recommendations are articulated: 
1. Heads of Departments should be given orientation at the time of appointment and retreat organised for them from time to time. These might not only expose them to the nature of position they are occupying and the expectations, but also prepare them effectively for the task of providing academic leadership.

2. There is need to prepare manual for HODs, which should be made available to them upon their appointment. This should clearly spell out their responsibilities, and the powers inherent in their positions. Through this, HODs are better equipped to succeed in the task of providing academic leadership.

3. Laid down policy of seniority should be strictly followed in the appointment of HODs. Appointing lecturers to this position based on favouritism is likely to enthrone mediocrity in departmental administrations and so slow down the pace of development of such university.

4. Modalities should be initiated at the university level whereby HODs are assessed from time to time, so as to find out areas of their strengths and weaknesses. This may not only propel them to be more effective, but also ensure that academic activities do not suffer from poor leadership.

\section{References}

Akuegwu, B.A., 2015. Research utilization in teaching among lecturers in South Nigerian universities: Extent, challenges and coping strategies. International Journal of Learning in Higher Education, 22(3): 45-55. View at Publisher

Ayuba, H.K., n.d. Departmental manual as an essential tool for effective management of academic departments in Nigerian universities. Challenges for Faculty Management at African Higher Education Institutions: 89.

Barakonyi, K., n.d. University governance: Overview and criticism on the Hungarian situation. Retrieved from http://www.drcsummerschool.eu/.

Berg, C.H. and C. Jarbur, 2014. Sustaining academic leadership. Retrieved from http://www.edin.ie/pubs/ei3-chapters/ei3-ch6.pdf.

Bolden, R., J. Gosling, A. O’Brien, K. Peters, M. Ryan and A. Haslam, 2012. Academic leadership: Changing conceptions, experiences and identities in higher education in UK universities. Final Report, Research \& Development Series. Leadership Foundation for Higher Education, London.

Bryman, A., 2007. Effective leadership in higher education: A literature review. Studies in Higher Education, 32(6): 693-710. View at Google Scholar $\mid$ View at Publisher

Chase, F.S., 2005. Factors for satisfaction in teaching. Phi Delta Kappa, 33: 129-139.

Drew, G., 2006. Balancing academic advancement with business effectiveness? The dual role for senior university leaders. International Journal of Knowledge, Culture and Change Management, 6(4): 117-125. View at Google Scholar

DuBrin, A.J., 2010. Principles of leadership. Int'l Edn., Melbourne, Australia: South-Western Cengage Learning.

Erkutlu, H., 2008. The impact of transformational on organisational and leadership effectiveness: The Turkish case. Journal of Management Development, 27(7): 708-726. View at Google Scholar | View at Publisher

Hesselbein, F. and M. Goldsmith, 2006. The leader of the future: Vision, strategies and practical for the new era. London: Wiley.

House, R.J., 2004. Preface. In R. J. House, P. J. Hanges, M. Javidan, P. W. Dorfman \& V. Gupta (Eds.), Culture, leadership, and organizations: The GLOBE study of 62 societies. Thousand Oaks, CA: Sage. pp: 22-28.

Jones, S., G. Lefoe, M. Harvey and K. Ryland, 2012. Distributed leadership: A collaborative framework for academics, executives and professionals in higher education. Journal of Higher Education Policy and Management, 34(1): 67-78. View at Google Scholar $\mid$ View at Publisher

Joyce, P. and C. O’Boyle, 2013. Sustaining academic leadership in higher education.

Kim, W.C. and R.A. Mauborgne, 1992. Parables of leadership. Harvard Business Review, 70(4): 123-128. View at Google Scholar

Lussier, R. and C.F. Achua, 2007. Leadership: Theory, application and skill development. Cincinnati, OH: South Western Publishing.

Lyons, M., 2008. The leadership role of head of departments at university. Unpublished Doctorate. University of South Africa, Pretoria, South Africa.

Riaz, H. and I. Haider, 2010. School district leadership that works. Denver: Mid-Continental Research for Education and Learning.

Sathye, M., 2004. Leadership in higher education: A qualitative study. In Forum Qualitative Sozialforschung/Forum: Qualitative Social Research, 5(3): View at Google Scholar

Skilbeck, M., 2001. The university challenged. A review of international trends and issues with particular reference to Ireland. Dublin: Higher Education Authority.

Sung, C.I., 2007. Relationship among supervisors' transformational and transactional leadership styles, and teachers' job satisfaction in Taiwan higher education. Unpublished Doctoral Dissertation, Lynn University.

University of Limerick, n.d. Academic profiles - roles and responsibility: Preamble. Retrieved from http://www.ul.ie/.

Vilkinas, T. and G. Cartan, 2006. The integrated competing values framework: Its spatial configuration. Journal of Management Development, 25(6): 505-521. View at Google Scholar | View at Publisher 